\title{
Reggies/flotillins regulate cytoskeletal remodeling during neuronal differentiation via CAP/ponsin and Rho GTPases
}

\author{
Matthias F. Langhorst ${ }^{\mathrm{a}, *}$, Friederike A. Jaeger ${ }^{\mathrm{a}, 1}$, Stephanie Mueller ${ }^{\mathrm{a}, 1}$, \\ L. Sven Hartmann ${ }^{\mathrm{b}}$, Georg Luxenhofer ${ }^{\mathrm{c}}$, Claudia A.O. Stuermer ${ }^{\mathrm{a}}$ \\ ${ }^{a}$ Department of Biology, University of Konstanz, Developmental Neurobiology Group, Universitätsstraße 10, \\ D 78457 Konstanz, Germany \\ ${ }^{\mathrm{b}}$ Institute of Neural Signaltransduction, Centre for Molecular Neurobiology, Falkenried 94, D 20251 Hamburg, Germany \\ ${ }^{\mathrm{c}}$ Institute of Physiology, University of Hohenheim, Garbenstraße 30, D 70593 Stuttgart, Germany
}

\begin{abstract}
The reggies/flotillins were discovered as proteins upregulated during axon regeneration. Here, we show that expression of a trans-negative reggie-1/flotillin-2 deletion mutant, R1EA, which interferes with oligomerization of the reggies/flotillins, inhibited insulin-like growth factor (IGF)-induced neurite outgrowth in N2a neuroblastoma cells and impaired in vitro differentiation of primary rat hippocampal neurons. Cells expressing R1EA formed only short and broad membrane protrusions often with abnormally large growth cones. R1EA expression strongly perturbed the balanced activation of the Rho-family GTPases Rac1 and cdc42. Furthermore, focal adhesion kinase (FAK) activity was also enhanced by R1EA expression, while other signaling pathways like ERK1/2, PKC or PKB signaling were unaffected. These severe signaling defects were caused by an impaired recruitment of the reggie/flotillin-associated adaptor molecule CAP/ponsin to focal contacts at the plasma membrane. Thus, the reggies/flotillins are crucial for coordinated assembly of signaling complexes regulating cytoskeletal remodeling.
\end{abstract}

Keywords: Reggies/flotillins; CAP/ponsin; Rho GTPases; Focal adhesion kinase; Focal adhesions; Cytoskeletal remodeling; Actin; Neurite outgrowth

\section{Introduction}

Axon regeneration after lesion depends on two major factors: a permissive surrounding and the re-expression of growth-associated proteins (Stuermer et al., 1992). While the glial cell environment surrounding lesioned axons

\footnotetext{
${ }^{*}$ Corresponding author at: Carl Zeiss MicroImaging GmbH, Konigsallee 9 21, D 37081 Gottingen, Germany.

Tel.: + 495515060 583; fax: + 495515060574 .

E mail address: Matthiaslanghorst@email.de (M.F. Langhorst).

${ }^{1}$ Both authors contributed equally.
}

of the mammalian central nervous system strongly inhibits axon outgrowth (Caroni and Schwab, 1993), the Schwann cells of the peripheral nervous system of mammals and oligodendrocytes of the central nervous system of fish promote axon outgrowth (Stuermer et al., 1992). This difference is one of the major causes leading to failure of regeneration in the central nervous system of mammals. On the other hand, a neuron has to re-initiate axon outgrowth upon injury and therefore has to reexpress growth-associated proteins, which represent the neuron-intrinsic determinants of successful regeneration (Fawcett, 1992; Stuermer et al., 1992). 
Reggie-1 and reggie-2 were discovered in our lab as proteins upregulated in retinal ganglion cells after optic nerve injury in goldfish and rat (Schulte et al., 1997; Lang et al., 1998). They were independently described as proteins abundant in the floating, detergent-resistant membrane fraction prepared from mouse lung tissue and therefore named flotillin-2 and -1, respectively (Bickel et al., 1997). The reggies/flotillins are evolutionarily highly conserved from fly to man (Galbiati et al., 1998; Malaga-Trillo et al., 2002). Via acylations at their $\mathrm{N}$-terminus, they associate with cellular membranes (Neumann-Giesen et al., 2004), where they form clusters of $50-100 \mathrm{~nm}$ by homo- and hetero-oligomerization, which is mediated by the C-terminal flotillin domain (Neumann-Giesen et al., 2004; Solis et al., 2007). The oligomeric reggie/flotillin clusters serve as membrane microdomain scaffolds for the regulated assembly of multiprotein signaling complexes (reviewed in Langhorst et al., 2005). Accordingly, the reggies were implicated in a variety of signaling pathways, e.g. in Glut4 translocation (Baumann et al., 2000), src-kinase signaling (Stuermer et al., 2001) or ABCA-1 function (Bared et al., 2004). Several reports linked the reggie/ flotillin proteins to cytoskeletal remodeling. Overexpression of reggie-1/flotillin-2 induced filopodia formation in epithelial cell lines (Hazarika et al., 1999; NeumannGiesen et al., 2004) and increased metastatic potential in melanoma cells (Hazarika et al., 2004). In T lymphocytes, the reggies/flotillins form preassembled, polarized platforms, upon which the $\mathrm{T}$ cell receptor signaling complex assembles after activation (Rajendran et al., 2003; Slaughter et al., 2003). The guanine-nucleotide exchange factor (GEF) Vav is constitutively associated with the reggie/flotillin scaffolds, and inhibition of reggie/flotillin function using a trans-negative reggie-1/ flotillin-2 deletion mutant perturbed specifically cytoskeletal remodeling after stimulation, while other early signaling pathways $\left(\mathrm{Ca}^{2+}\right.$ signaling or ZAP-70 phosphorylation) were not affected (Langhorst et al., 2006b).

Having established a role of the reggies/flotillins in $\mathrm{T}$ cell actin remodeling, we suspected that they might play a similar role in neurons - as their discovery during axon regeneration suggests. To build up the complex morphology of a mature neuron, the original round shape of the undifferentiated cell has to change dramatically during neurite extension and differentiation of the axon and dendrites. These processes are highly dependent on regulated remodeling of the cytoskeleton. Actin is the driving force of newly formed membrane protrusions, and microtubules stabilize neurites thereafter (da Silva and Dotti, 2002). The actual actin remodeling during neurite outgrowth is controlled by actin-binding proteins like profilin, cofilin, Arp2/3, the WASP complex, and filamin (reviewed in Revenu et al., 2004). Their activity in turn is regulated by various signaling cascades, among which the Rho-family GTPases are well established key players (Hall, 1998; Burridge and Wennerberg, 2004).

We show here that the reggies/flotillins are crucial for controlled and balanced cytoskeletal remodeling during neuronal differentiation. Expression of a trans-negative reggie-1/flotillin-2 mutant R1EA inhibited neurite outgrowth after IGF-1 stimulation in N2a neuroblastoma cells and perturbed in vitro differentiation of primary rat hippocampal neurons. Recruitment of $\mathrm{CAP} /$ ponsin to focal contacts was impaired in R1EA-expressing cells, leading to an imbalanced activation of Rho GTPases and an enhanced activity of FAK, while other signaling pathways were not affected.

\section{Material and methods}

\section{Antibodies and reagents}

Anti-reggie-1/flotillin-2 (ESA), anti-FAK, anti-paxillin and anti-Racl monoclonal antibodies $(\mathrm{mAB})$ were purchased from BD Transduction Laboratories (Heidelberg, Germany), anti-CAP/ponsin polyclonal antibodies were from Upstate (Charlottesville, USA), anti-RhoA and anti-cdc42 mAB were from Santa Cruz (Santa Cruz, USA), anti-Ras mAB from Oncogene/Calbiochem (Bad Soden, Germany), and anti-HA mAB (rat) from Roche (Mannheim, Germany). Phosphorylation-specific antibodies against PKB (Ser473), pan-PKC (Ser660 and homologues residues), ERK1/2 (Thr202/Tyr204), JNK (Thr183/Tyr185), FAK (Tyr576/577), and p38 (Thr180/ Tyr182) were from Cell Signaling Technology (Beverly, MA, USA). Secondary antibodies coupled to HRP or Cy3 were from Jackson ImmunoResearch (Soham, UK), and secondary antibodies coupled to Alexa488 were from Molecular Probes (Leiden, The Netherlands).

Reggie/flotillin full-length and deletion constructs were described earlier (Neumann-Giesen et al., 2004; Langhorst et al., 2006b).

\section{Cell culture and transfection}

N2a neuroblastoma cells were cultivated and transfected as described previously (Langhorst et al., 2006a), transfection efficiency under these conditions was $\sim 70 \%$. For microscopic analysis, cells were grown on 25-mm coverslips coated with poly-L-lysine and laminin (Sigma) and mounted in an Attofluor chamber (Invitrogen, Karlsruhe, Germany). For differentiation, cells were plated on laminin-coated coverslips and cultured in MEM containing $50 \mathrm{ng} / \mathrm{ml}$ IGF-1 (Biomol, Hamburg, Germany) but no FCS. IGF is known to prevent apoptosis and induce neurite outgrowth in N2a and a variety of other neuroblastoma cells (Recio-Pinto et al., 1986; Kim et al., 1997). 
Primary rat hippocampal neurons were prepared at embryonic day 18 (E18). Briefly, Wistar rats were anaesthetized by inhalation of $\mathrm{CO}_{2}$ and decapitated. Embryos were removed and isolated hippocampal tissue digested and homogenized. Cells were plated on poly-Llysine-coated coverslips in plating medium (MEM supplemented with $0.6 \%$ glucose and $10 \%$ horse serum), after $3 \mathrm{~h}$ the medium was changed to Neurobasal containing B27 supplement and $0.5 \mathrm{mM}$ L-glutamine (enriched Neurobasal, all Invitrogen). Glutamate $(25 \mu \mathrm{M})$ was included for the first 3 days after plating. Neurons were transfected using the calcium phosphate method as described previously (Fuhrmann et al., 2002). Twenty-four hours after transfection cells were collected by trypsinization and plated on new coverslips. Seventytwo hours post transfection cells were fixed using Histofix (Roth, Karlsruhe, Germany) and mounted.

\section{Cell lysates, GTPase assays and Western blotting}

Cells were starved overnight, stimulated with $50 \mathrm{ng} / \mathrm{ml}$ IGF-1 and lysed in ice-cold kinase lysis buffer $(20 \mathrm{mM}$ Tris-HCl, pH 7.5, $2 \mathrm{mM}$ EDTA, $100 \mathrm{mM} \mathrm{NaCl}, 5 \mathrm{mM}$ $\mathrm{MgCl}_{2}, 1 \%$ (v/v) Triton-X-100, 10\% (v/v) glycerol, supplemented with phosphatase inhibitor cocktail II (Calbiochem) and Roche mini complete protease inhibitors (Roche, Mannheim, Germany)). Cleared lysates were either directly used for Western blotting or incubated with glutathione-agarose coupled to GSTPak1-RBD, GST-Raf-RBD or GST-Rhotekin-RBD (Upstate) for the precipitation of GTP-Racl/GTPcdc42, GTP-Ras or GTP-RhoA, respectively. Beads were extensively washed in kinase lysis buffer, bound proteins were eluted by boiling in SDS sample buffer and analyzed by Western blotting. Western blotting was performed according to standard procedures using Immobilon-P PVDF membranes (Millipore, Billerica, MA, USA), HRP-coupled secondary antibodies and SuperSignal chemiluminescence detection (Pierce, Rockford, USA). Co-immunoprecipitations were carried out as described previously (Langhorst et al., 2006b).

\section{Microscopy}

For widefield imaging an Axiovert 200M with a $40 \times 1$ 1.3 Plan-Neofluar or a $63 \times / 1.4$ Plan-Apochromat objective was used in combination with an AxioCam $\mathrm{MRm}$ with a full resolution of $1388 \times 1040$ pixels. For total internal reflection fluorescence (TIRF) illumination the TIRF slider system with a multi-line argon laser was used in combination with a $100 \times / 1.45 \alpha$ Plan-Fluar objective (all Carl Zeiss, Jena, Germany). Interference reflection microscopy was carried out using a 565/30 bandpass filter, a 50R/50T mirror and no emission filter. Confocal images were acquired on an LSM 510 META with a $63 \times / 1.4$ Plan-Apochromat or a $100 \times / 1.45$ $\alpha$ Plan-Fluar objective. Images were processed using the LSM 510 software, AxioVision 4.5 (both Carl Zeiss) and ImageJ (Abramoff et al., 2004).

\section{Results}

We have previously shown that expression of the isolated oligomerization domain of reggie-1/flotillin-2 (named R1EA, Fig. 1A) has a trans-negative effect on reggie/flotillin function in $\mathrm{T}$ cells (Langhorst et al., 2006b). By interfering with the oligomerization of the endogenous proteins, R1EA impaired correct positioning of the reggies/flotillins in $\mathrm{T}$ cells (Langhorst et al., 2006b). In N2a cells, expression of R1EA similarly impeded membrane-association of e.g. reggie-2/flotillin1. Upon co-expression with R1EA, reggie-2/flotillin-1EGFP was retained to a large extent in the cytosol of N2a cells, while in cells co-expressing reggie-2/flotillin-1EGFP and DsRed as a control, reggie-2/flotillin-1EGFP clearly associated with the plasma membrane (Fig. 1B and C). To quantify this effect, we calculated the ratio between the mean fluorescence intensity of a region of interest (ROI) at the plasma membrane over the mean fluorescence intensity of an ROI in the cytosol as indicated in Fig. 1B and C. For control cells this ratio was $3.7 \pm 0.4$, while for R1EA-expressing cells, it was $1.4 \pm 0.6$ (23 and 27 cells, respectively, $p<0.001$ Student's $t$-test). Thus, as shown previously in $\mathrm{T}$ cells, R1EA expression severely impaired correct localization of full-length reggies/flotillins.

Importantly, expression of R1EA led to profound defects in differentiation of N2a cells induced by IGF-1. The number of R1EA-expressing cells forming neurites was significantly lower $(p<0.001$, chi square test) compared to mock-transfected cells expressing EGFP as controls (Fig. 2A-C). Furthermore, the neurites still formed by R1EA-expressing cells were significantly shorter $(p<0.01$, Student's $t$-test $)$ compared to mocktransfected cells (Fig. 2D). Instead of cylindrical neurites, R1EA-expressing cells often formed broad membrane protrusions of lamellipodial character (Fig. 2B). Importantly, similar effects of R1EA on neurite formation were observed in the phaeocytochroma PC12 cell line after induction of differentiation with $\mathrm{NGF}$ (data not shown). Overexpression of the full-length reggies/flotillins tagged with EGFP had no effect on IGF-induced neurite outgrowth in N2a or PC12 cells (data not shown).

To further investigate the effects of expression of the trans-negative reggie/flotillin mutant R1EA during differentiation, we analyzed the actin and tubulin cytoskeleton during early and late phases of differentiation. Both, in cells just attached to the laminin-coated 
(A)

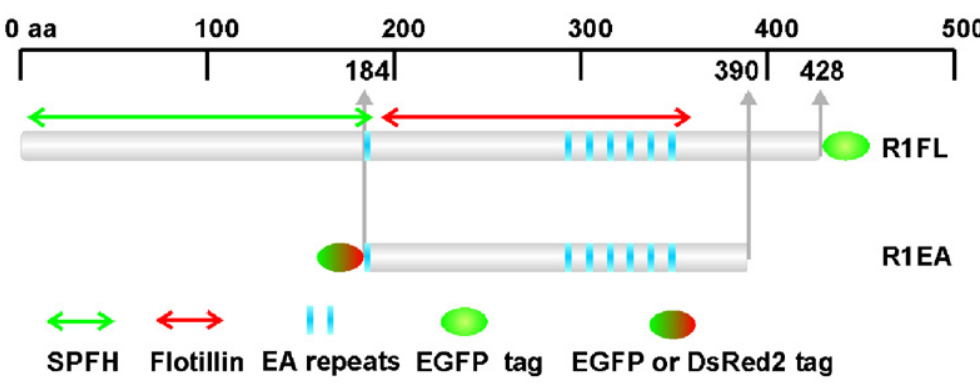

(B)
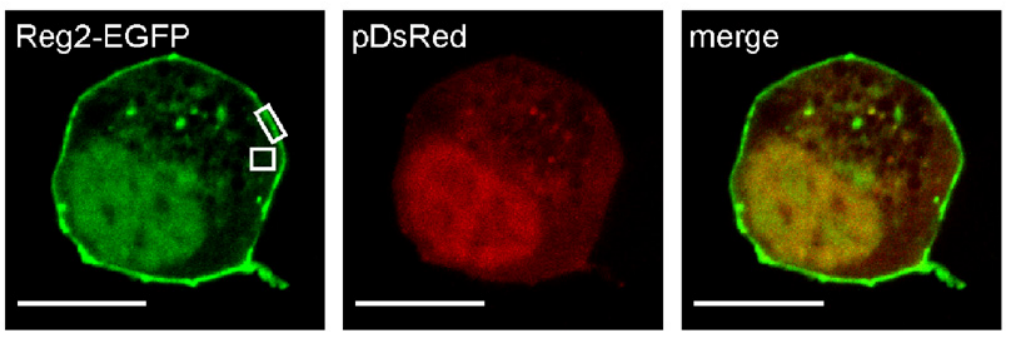

(C)
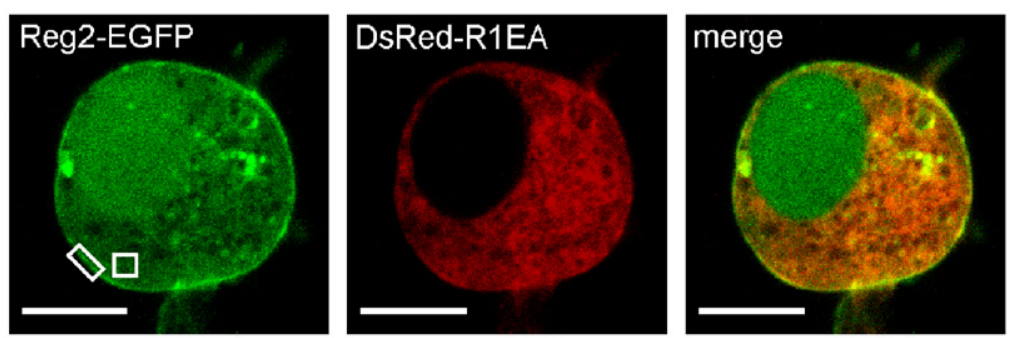

Fig. 1. R1EA impedes membrane association of reggie 2/flotillin 1. (A) Schematic representation of the trans negative reggie 1/ flotillin 2 deletion mutant R1EA. (B and C) N2a cells were transfected with EGFP tagged reggie 2/flotillin 1 and DsRed R1EA or pDsRed, respectively, grown on poly L lysine and imaged $20 \mathrm{~h}$ after transfection. Note the impaired membrane association of reggie 2/flotillin 1 upon co expression with DsRed R1EA. The white rectangular ROIs were used to calculate the mean fluorescence at the plasma membrane and in the cytosol, respectively. Bars: $10 \mu \mathrm{m}$.

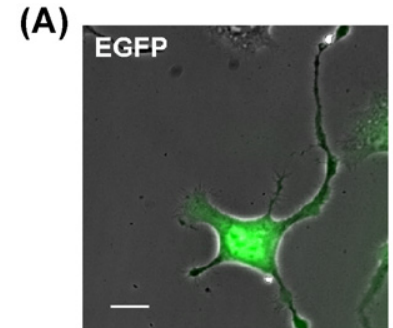

(B)

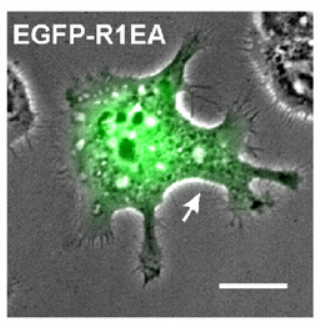

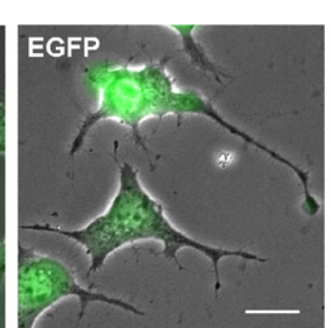

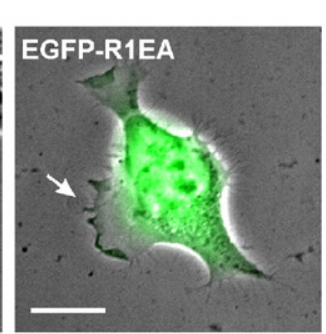

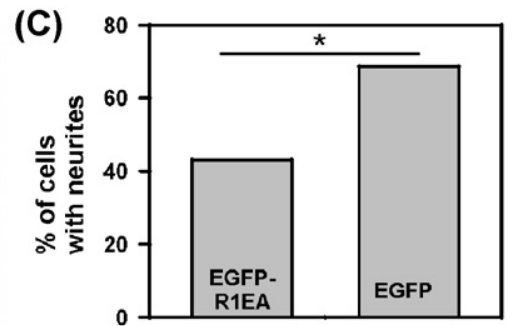

(D)

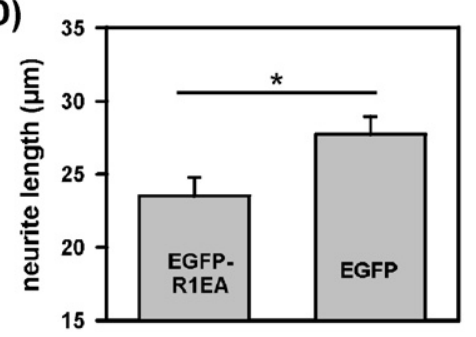

Fig. 2. R1EA disturbs neurite outgrowth in N2a cells. N2a cells were transfected with pEGFP (A) or EGFP R1EA (B) and transferred to laminin coated coverslips in IGF containing, serum free medium $24 \mathrm{~h}$ after transfection. Forty eight hours after transfection, 207 (pEGFP) or 234 (EGFP R1EA) cells from 3 independent experiments were analyzed for number of neurite bearing cells (C) and length of neurites (D). *Indicates statistical significance. Note the severe impairment of neurite outgrowth in R1EA expressing cells and the broad, lamellipodia like protrusions formed by R1EA expressing cells instead of cylindrical neurites. Bars: $10 \mu \mathrm{m}$. 

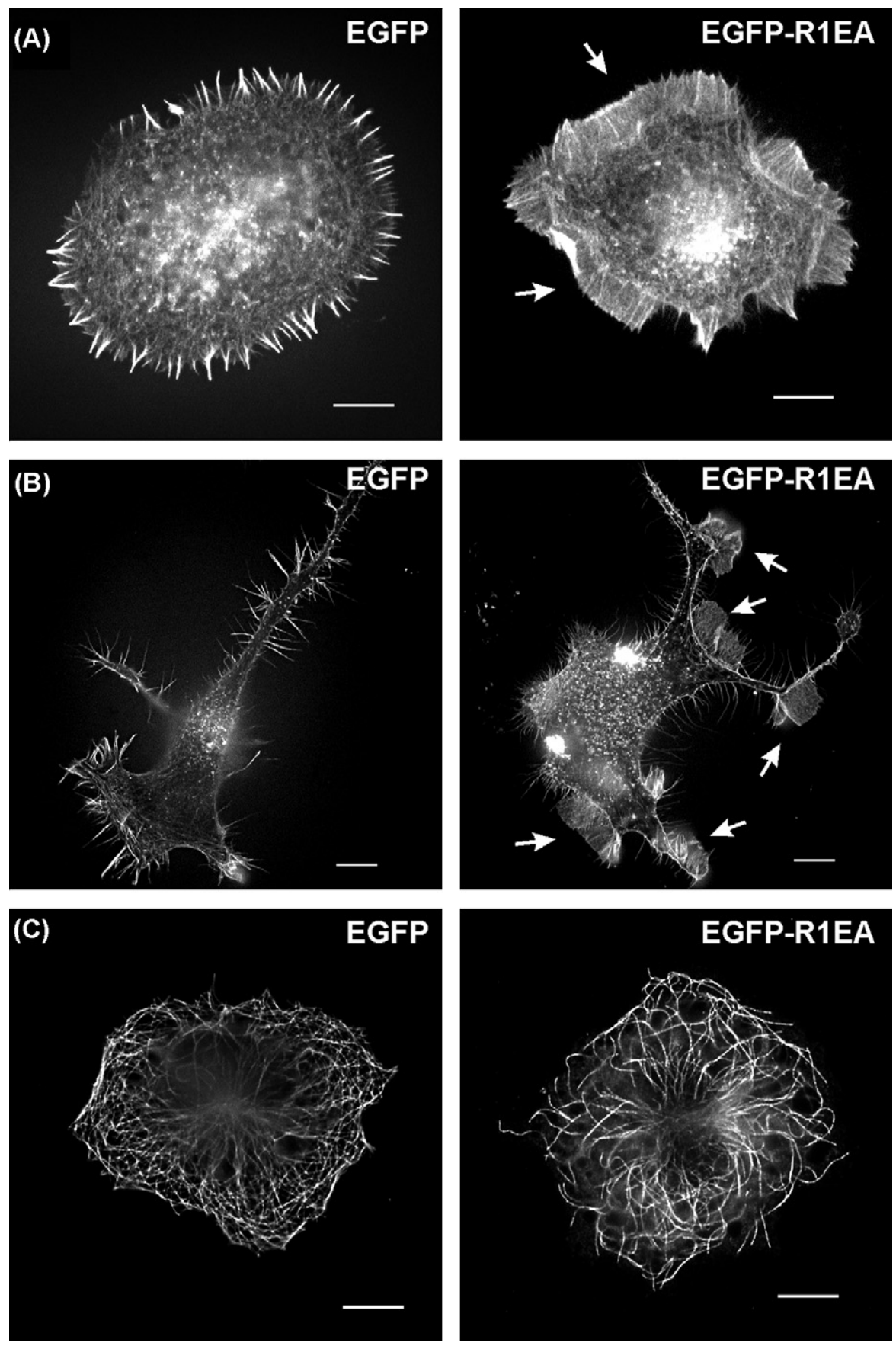

Fig. 3. R1EA severely disturbs cytoskeletal remodeling during differentiation. N2a cells were transfected with EGFP or EGFP R1EA and transferred to laminin coated coverslips in IGF containing, serum free medium $24 \mathrm{~h}$ after transfection. (A) $29 \mathrm{~h}$ and (B) $48 \mathrm{~h}$ post transfection, the actin cytoskeleton was stained with phalloidin Alexa 555. A large proportion of R1EA expressing cells exhibited numerous lamellipodia in both stages of differentiation. (C) Similarly, the tubulin cytoskeleton was stained by indirect immunofluorescence $29 \mathrm{~h}$ post transfection, which was disordered in R1EA expressing cells. Bars: $10 \mu \mathrm{m}$.

coverslip and starting to differentiate (Fig. 3A) and in already largely differentiated cells (Fig. 3B), we observed the formation of numerous lamellipodia on R1EAexpressing cells, but clearly less on control cells. Filopodia formed by R1EA-expressing cells were on average significantly shorter than those formed by control cells $(5.3 \mu \mathrm{m}$ (R1EA) vs. $6.4 \mu \mathrm{m}$ (EGFP), $p<0.01,121$ and 137 cells, respectively, from 5 independent experiments). These results suggest that actin remodeling during differentiation is severely affected by expression of the trans-negative reggie/ flotillin mutant. Furthermore, the tubulin cytoskeleton 
was altered; in many R1EA-expressing cells it appeared less organized. No stabilizing dense tubulin network could be found in R1EA-expressing cells, only thick bundles (Fig. 3C). The positioning and orientation of the microtubule-organizing centre (MTOC) was, however, not changed by R1EA expression (data not shown).

To verify the physiological importance of the reggies/ flotillins for neuronal differentiation, we tested whether R1EA affects in vitro differentiation of primary rat hippocampal neurons. The majority of cells fully differentiated in the presence of enriched Neurobasal within $48 \mathrm{~h}$ when transfected with pEGFP as controls (Fig. 4A and C). Cells transfected with R1EA, however, exhibited significantly impaired differentiation and striking phenotypes (Fig. 4B and C). The majority of R1EA-expressing cells formed only short axons, often with abnormally large growth cones (Fig. 4B, arrows). The bases of dendrites were also often broadened (Fig. 4B, arrowhead). Only few R1EA-expressing cells reached a fully differentiated morphology (Fig. 4C). The phenotypes observed in primary neurons correlate well
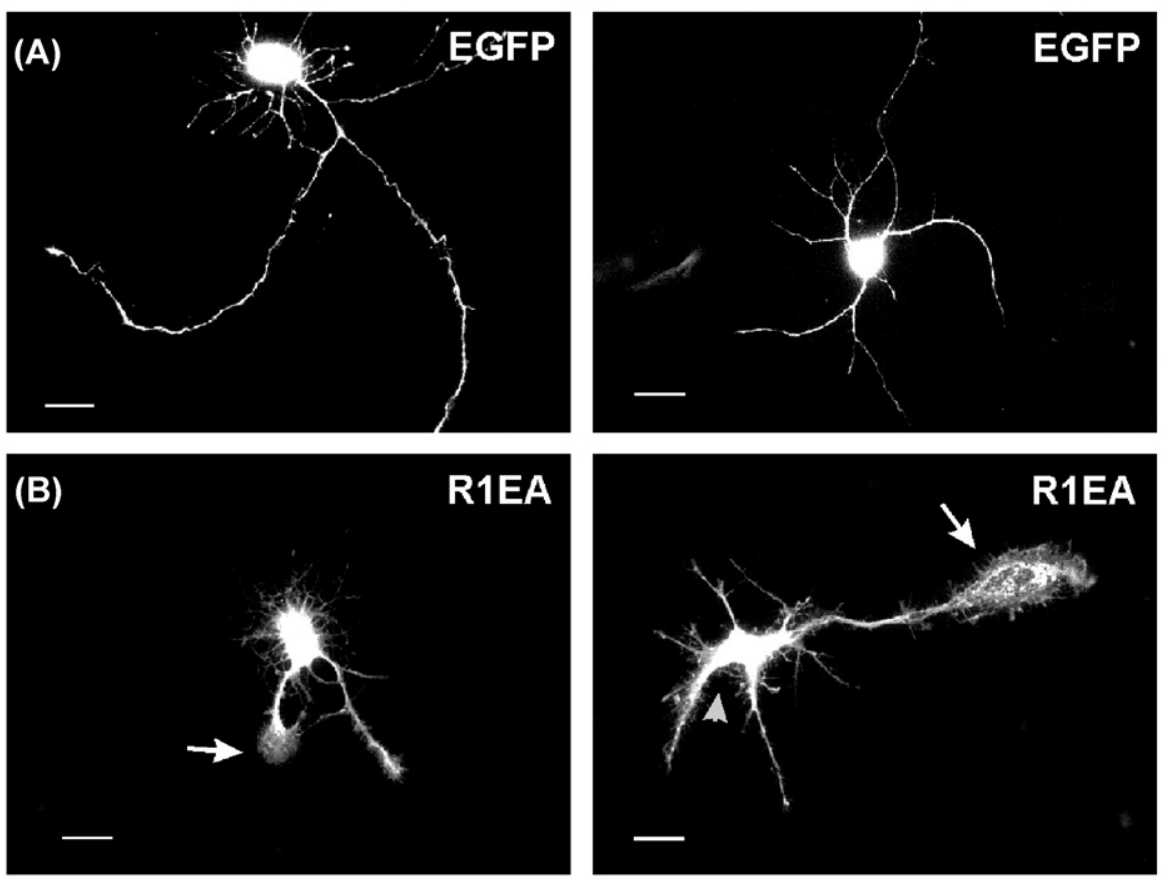

(C)

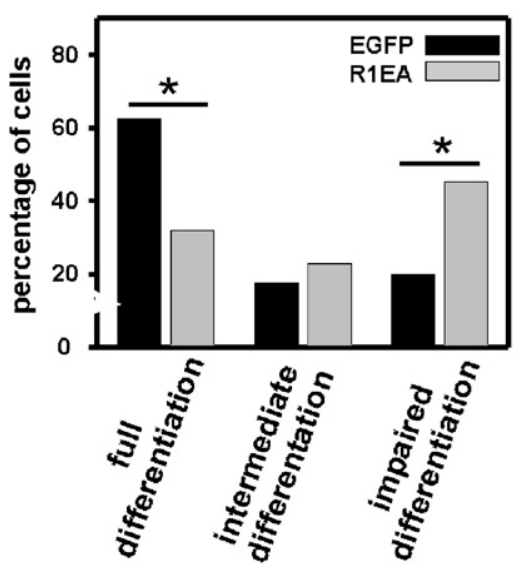

Fig. 4. R1EA inhibits in vitro differentiation of primary hippocampal neurons. Rat primary hippocampal neurons were prepared as detailed in Materials and methods. Cells were transfected with EGFP R1EA or pEGFP, transferred to new coverslips $24 \mathrm{~h}$ post transfection and differentiated in the presence of enriched Neurobasal. For quantitative analysis, 80 (EGFP) and 75 (R1EA) cells from three independent experiments were evaluated. Note the short axons, large growth cones (white arrows) and broad dendrites (arrowhead) of R1EA expressing cells, while control transfected cells differentiated normally (A and B). (C) Cells were grouped into three categories (cells in (A) are examples of full differentiation, cells in (B) are examples of impaired and intermediate differentiation, respectively). R1EA expression significantly shifted the distribution towards impaired differentiation $\left(p<0.001, \chi^{2}\right.$ test). Bars: $10 \mu \mathrm{m}$. 
with our results from neuroblastoma cells, thus confirming the essential role of the reggies/flotillins in neuronal differentiation.

The phenotypes observed in R1EA-expressing cells suggested a severe impairment of cytoskeletal remodeling caused by the expression of the trans-negative reggie-1/flotillin-2 mutant. Therefore, we next investigated the effects of R1EA expression on signaling pathways known to be involved in cytoskeleton remodeling. We assayed the activation of small GTPases of the Rho family by GST-pulldown with minimal binding domains of effector proteins specific for the GTP-bound form of the GTPase - as pioneered for Ras using the minimal Ras-binding domain of Raf coupled to GST (de Rooij and Bos, 1997). In accordance with the severe defects observed in neurite outgrowth, these assays revealed a drastic alteration of the activation patterns of the small GTPases Rac1 and cdc42. Activation of Rac1 by IGF-1 was almost completely blocked by expression of R1EA, while in mocktransfected cells IGF-1 induced a strong activation of Rac1 (Fig. 5). In contrast, cdc42 activity was strongly enhanced in resting cells expressing R1EA, and IGF-1 stimulation of these cells induced only a small increase in cdc42-GTP levels. In control cells, nearly no cdc42GTP could be detected in resting cells but IGF-1 induced a strong increase in cdc42-GTP levels (Fig. 5). Activation of Ras was undistinguishable in R1EAexpressing cells and mock-transfected cells (Fig. 5), similarly RhoA activation was not significantly altered in R1EA-expressing cells (data not shown). Thus, expression of the trans-negative reggie-1/flotillin-2 deletion mutant R1EA leads to an imbalanced activation of small GTPases of the Rho family, while Ras activation is not affected.

Using phospho-specific antibodies against some key signaling proteins we tested whether R1EA also interfered with activation of other signaling pathways. The general level of FAK tyrosine phosphorylation at residues 567 and 577 was strongly enhanced in R1EA- expressing cells (Fig. 6A) while the relative response to IGF was not changed (data not shown). Expression of R1EA had no effect on the phosphorylation of the MAP kinases ERK $1 / 2$ and JNK by IGF-1 (Fig. 6B). Phosphorylation of $\mathrm{PKB}$ and $\mathrm{PKC}$ were also not affected by R1EA expression (Fig. 6C). siRNAmediated knockdown of reggie-1/flotillin-2 had similar effects on signaling and morphology of neuronal cells (C. Munderloh and C.A.O. Stuermer, unpublished results).

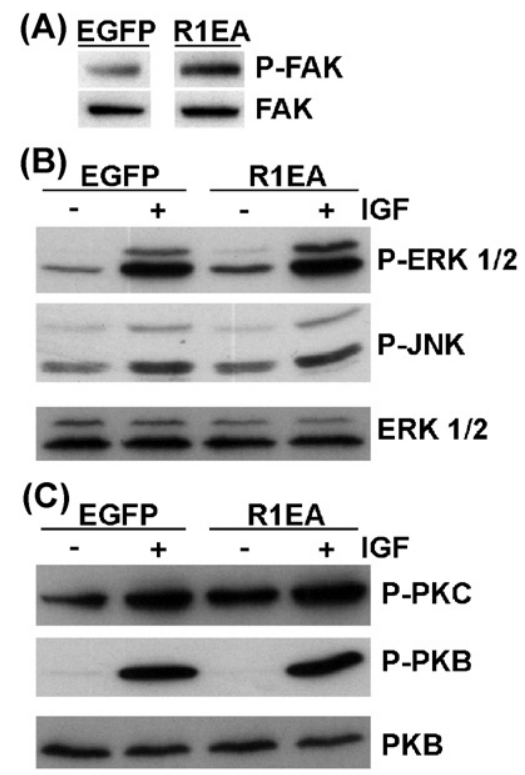

Fig. 6. MAP kinase, $P K B$ and $P K C$ signaling in IGF stimulated N2a cells expressing R1EA. N2A cells were transfected with pEGFP and EGFP R1EA, serum deprived overnight, and stimulated with $50 \mathrm{ng} / \mathrm{ml} \mathrm{IGF} 1$ for $5 \mathrm{~min}$. Phosphorylation of key signaling molecules was assessed using phospho specific antibodies. Representative blots of 58 independent experiments are shown. Total ERK1/2, total PKB and total FAK were used as loading controls. FAK phosphorylation was elevated by R1EA expression (A); ERK1/2, JNK phosphorylation (B) and PKC and PKB signaling $(\mathrm{C})$ was not affected by R1EA.
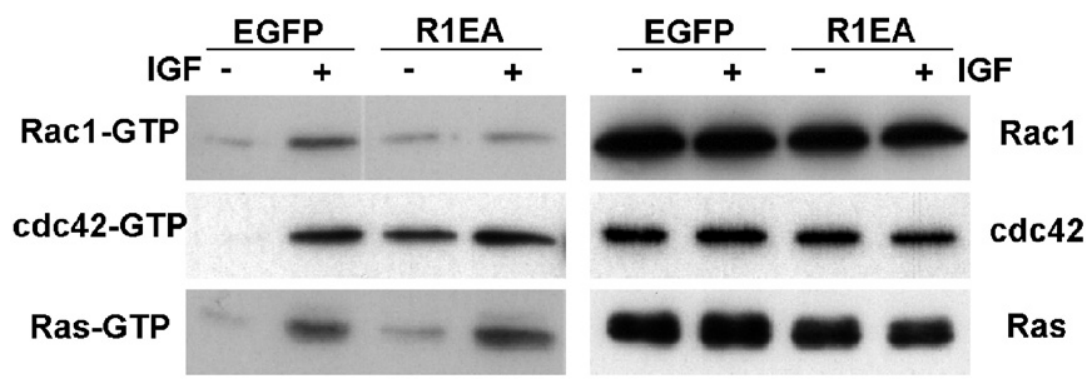

Fig. 5. Rho GTPase signaling after IGF stimulation in N2a cells expressing R1EA. N2A cells were transfected with pEGFP and EGFP R1EA, serum deprived overnight, and stimulated with $50 \mathrm{ng} / \mathrm{ml} \mathrm{IGF} 1$ for $5 \mathrm{~min}$. GTP loading of small GTPases was assayed as detailed in Materials and methods. Western blots of crude lysates are shown as controls for equal loading. The result shown is representative of 48 independent experiments. R1EA expression almost completely inhibited IGF stimulated Rac1 activation and strongly enhanced cdc42 activation in resting cells, while Ras activation was unaffected. 
These results suggest that interference with reggie/ flotillin function selectively interferes with signaling pathways to the cytoskeleton. Reggie-2/flotillin-1 is known to interact with proteins of the vinexin family (Kimura et al., 2001), which are crucial adaptors in signaling pathways to actin remodeling (Kioka et al., 2002). The vinexin-family member $\mathrm{CAP} /$ ponsin is expressed in N2a cells, predominantly in a known splice variant of $100 \mathrm{kDa}$, while expression of vinexin- $\alpha$ and $-\beta$ could not be detected (data not shown). CAP/ponsin clearly co-localized both with reggie-1/flotillin-2 and reggie-2/flotillin-1 in clusters at the basal plasma membrane of N2a cells as observed by TIRF microscopy (Fig. 7A and B). These clusters were points of close contact of the cell with the substrate as shown by interference reflection microscopy (data not shown). Additionally, FAK (Fig. 7C) and paxillin (data not shown) could be found in these clusters, identifying them as focal adhesions. To formally prove the interaction of $\mathrm{CAP} /$ ponsin with the reggies/flotillins, we carried out co-immunoprecipitation experiments of endogenous $\mathrm{CAP} /$ ponsin and the endogenous reggies/ flotillins. After immunoprecipitation of $\mathrm{CAP} /$ ponsin, reggie-1/flotillin-2 could be reliably detected in the precipitate (Fig. 7D), thus proving that not only reggie-2/flotillin-1 but also reggie-1/flotillin-2 can interact with $\mathrm{CAP} /$ ponsin.

Most interestingly, expression of the trans-negative reggie-1/flotillin-2 mutant R1EA significantly inhibited the recruitment of $\mathrm{CAP} /$ ponsin to the plasma membrane. $\mathrm{CAP} /$ ponsin staining of the basal plasma membrane as observed by TIRF microscopy was low and largely diffuse in R1EA-expressing cells instead of clustered in focal adhesions as in control cells (Fig. 8A). The clustering of paxillin (Fig. 8B) and FAK (data not shown), however, was not affected by R1EA expression. R1EA expression did not alter the expression level of $\mathrm{CAP} /$ ponsin (Fig. 8C). This suggests that reggie/flotillin localization to focal contacts is essential for the recruitment of $\mathrm{CAP} /$ ponsin, but not for focal contact assembly itself.

\section{Discussion}

The results of this study can be summarized as follows: In neurons, the reggies/flotillins are necessary for the recruitment of vinexin-family adaptor proteins to the plasma membrane and especially to focal contacts. Failure of membrane recruitment, as in cells expressing a trans-negative reggie-1/flotillin-2 mutant, leads to enhanced FAK activity and an imbalanced activity of Rho-family GTPases. This strongly impairs cytoskeletal remodeling and consequently neurite outgrowth both in neuroblastoma cells and in primary rat hippocampal neurons, while other signaling pathways, such as PKB or ERK1/2 signaling are unaffected. In most of these experiments, we have worked with cells early in differentiation, but we strongly believe that the results obtained can be extrapolated to later stages of neurite outgrowth and axon extension as shown by our results demonstrating impaired differentiation of hippocampal neurons.

The vinexin-family adaptor proteins vinexin, CAP/ ponsin and $\mathrm{ArgBP} 2$ act as integrators of growth factor signaling and signaling from cell-substrate contact sites, like focal adhesions (Kioka et al., 2002; Suwa et al., 2002; Mitsushima et al., 2004). CAP/ponsin was shown to localize to focal adhesions of 3T3 fibroblasts, where it interacts with FAK (Ribon et al., 1998). Overexpression of CAP/ponsin in these cells led to decreased tyrosine phosphorylation of FAK (Ribon et al., 1998). This is in good agreement with our data showing an increased tyrosine phosphorylation of FAK after loss of CAP/ ponsin membrane recruitment. Interestingly, FAK is a key integrator of signaling during neurite outgrowth: FAK activity not only integrates integrin and growth factor signaling, but also signaling from guidance cues like ephrins or netrins (Davy and Robbins, 2000; Ren et al., 2004).

In addition to its role in regulating FAK activity, our results show that reggie/flotillin-mediated recruitment of $\mathrm{CAP} /$ ponsin to focal contacts is crucial for the balanced activation of the Rho-family GTPases. CAP/ponsin is known to interact directly with Sos and indirectly with other GEFs via the adaptor protein Grb4 (Kioka et al., 2002), which makes it a key adaptor and regulator controlling a variety of GTPases. The regulated interaction of different Rho GTPases is critical in neurite outgrowth. As mentioned above, a variety of studies suggests that RhoA activity generally inhibits, while cdc42 and Rac activity generally enhances neurite outgrowth. But recent studies suggested that the picture might be more complex. Both constitutive-active and dominant-negative Rac1 mutants inhibited neurite outgrowth in chick embryo motor neurons (Kuhn et al., 1998). Furthermore, live imaging of Rho GTPase activation in neurons using FRET reporter constructs showed that all three classical Rho GTPases, RhoA, Rac1 and cdc42, undergo repetitive activation and inactivation cycles at motile protrusions, with different localizations of their respective peak activity (Aoki et al., 2004; Kurokawa et al., 2005; Nakamura et al., 2005). Thus, a finely tuned interplay of different Rho GTPases is apparently necessary for successful neurite outgrowth. The Rho GTPases are not only necessary for the actindependent formation of the initial membrane protrusions, but also for the control of microtubuli dynamics during stabilization of the outgrowing neurite (da Silva and Dotti, 2002). Thus, the broad, lamellipodia-like protrusions formed by R1EA-expressing cells reflect 


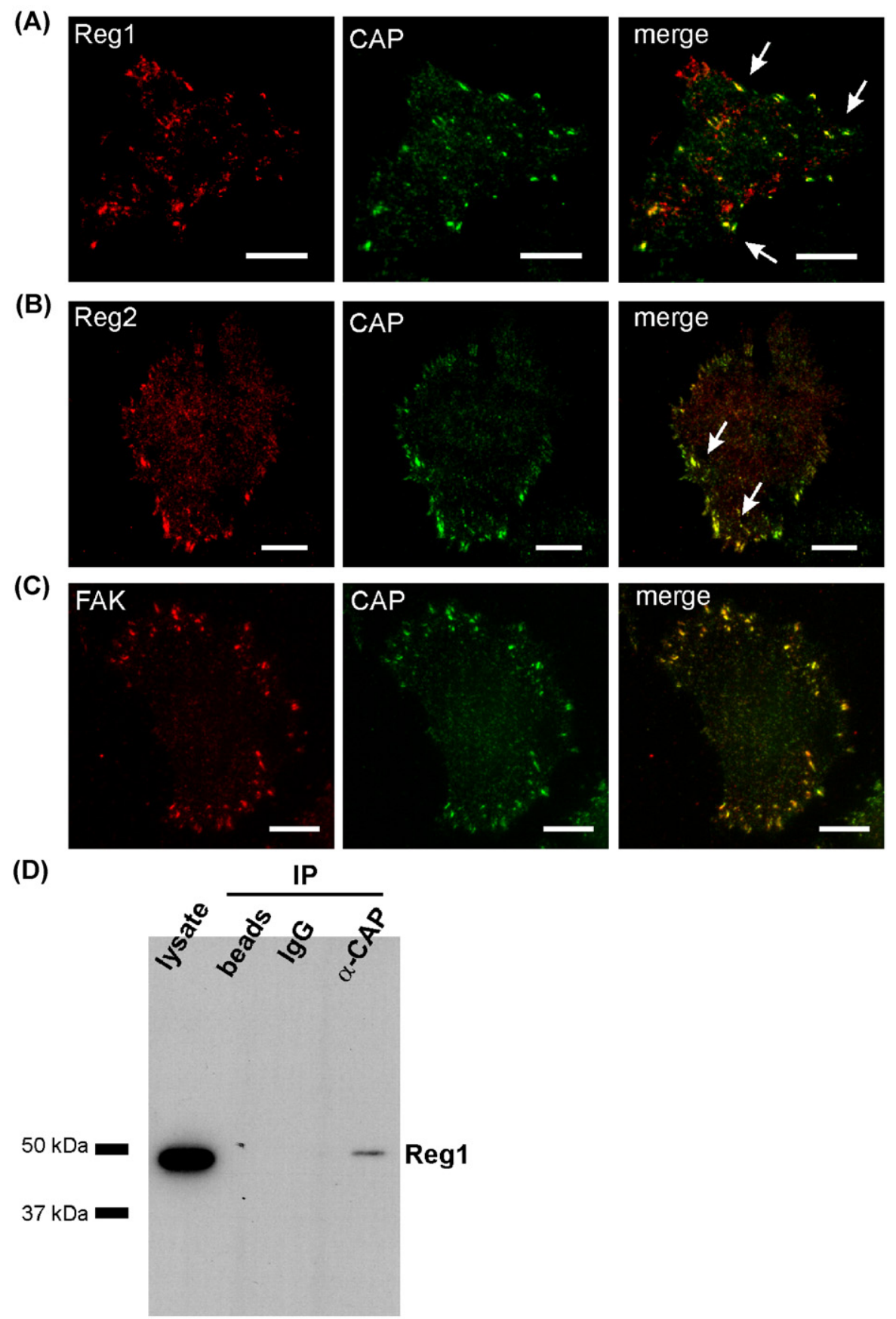

Fig. 7. Reggies/flotillins and CAP/ponsin co localize in focal contacts. (A, B) N2a cells were grown on laminin and transfected with HA tagged reggie 1/flotillin 2 and reggie 2/flotillin 1. Eighteen hours after transfection cells were fixed, immunostained for CAP/ ponsin and HA and imaged using TIRF microscopy. Both reggie 1/flotillin 2 and reggie $2 /$ flotillin 1 accumulated in CAP/ponsin positive clusters. (C) Cells were grown for $24 \mathrm{~h}$ on laminin, fixed, immunostained for CAP/ponsin and FAK and imaged by TIRF microscopy. The CAP/ponsin clusters co localize with FAK. (D) Co immunoprecipitations were carried out as detailed in Materials and methods, a representative blot from 3 independent experiments is shown. Precipitation of endogenous CAP/ponsin reliably co precipitated endogenous reggie 1 /flotillin 2. Bars: $10 \mu \mathrm{m}$.

most probably both, the impaired actin remodeling and the failure to transform membrane protrusions to cylindrical neurites by stabilization through microtubules.
We have recently shown, that reggie-1/flotillin-2 is able to bind to filamentous actin via its SPFH domain (Langhorst et al., 2007), making reggie/flotillin oligomers ideal platforms for the recruitment of signaling 

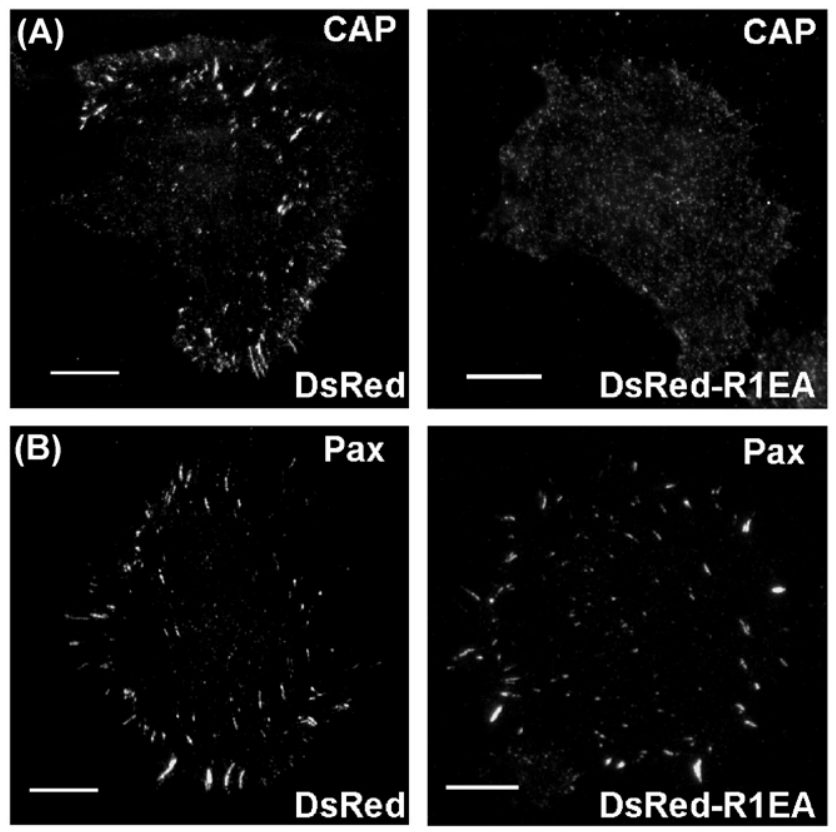

(C) EGFP R1EA

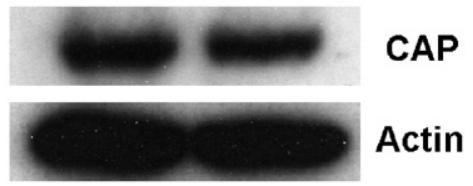

Fig. 8. R1EA inhibits $C A P /$ ponsin recruitment to the plasma membrane. (A, B) Cells were transfected with pDsRed or DsRed R1EA, transferred to laminin coated coverslips $24 \mathrm{~h}$ post transfection, fixed and stained for CAP (A) and paxillin (B) $48 \mathrm{~h}$ post transfection. R1EA expression inhibited CAP/ ponsin clustering at the plasma membrane. (C) R1EA expression did not lead to a change in $\mathrm{CAP} /$ ponsin protein levels as judged by Western blotting. Bars: $10 \mu \mathrm{m}$.

complexes regulating cytoskeletal dynamics. Scaffolding proteins contribute to the specificity of GTPase signaling by bringing the GTPases, their regulators and specific effectors in close proximity. The involvement of reggie/flotillin scaffolds in GTPase signaling, as shown in this study for neurons, was also suggested by studies in two other cell types. Upon insulin stimulation of adipocytes, reggie-2/flotillin-1 was shown to recruit a multiprotein complex to the membrane, which finally resulted in the activation of the small GTPase TC10 via $\mathrm{CAP} /$ ponsin and c-Cbl-mediated recruitment of CrkIIIC3G (Baumann et al., 2000). We have previously shown that in $\mathrm{T}$ lymphocytes, reggie-1/flotillin-2-dependent positioning of the GEF Vav is essential for actin remodeling after activation, while other early signaling pathways were unaffected (Langhorst et al., 2006b). Thus, it is well conceivable that regulating the assembly of Rho GTPase signaling complexes and thus cytoskeleton remodeling is a general function of reggie/flotillin microdomains in many different cell types.

\section{Acknowledgments}

This work was supported by grants from the Deutsche Forschungsgemeinschaft DFG (SFB-TR11), the Ministerium Forschung, Wissenschaft und Kunst BadenWürttemberg (TSE program) and the Fonds der Chemischen Industrie.

\section{References}

Abramoff, M.D., Magelhaes, P.J., Ram, S.J., 2004. Image processing with imageJ. Biophoton. Int. 11, 3642.

Aoki, K., Nakamura, T., Matsuda, M., 2004. Spatio temporal regulation of Rac1 and Cdc42 activity during nerve growth factor induced neurite outgrowth in PC12 cells. J. Biol. Chem. 279, 713719.

Bared, S.M., Buechler, C., Boettcher, A., Dayoub, R., Sigruener, A., Grandl, M., Rudolph, C., Dada, A., Schmitz, G., 2004. Association of ABCA1 with syntaxin 13 and flotillin 1 and enhanced phagocytosis in tangier cells. Mol. Biol. Cell 15, 53995407.

Baumann, C.A., Ribon, V., Kanzaki, M., Thurmond, D.C., Mora, S., Shigematsu, S., Bickel, P.E., Pessin, J.E., Saltiel, A.R., 2000. CAP defines a second signalling pathway required for insulin stimulated glucose transport. Nature 407, 202207.

Bickel, P.E., Scherer, P.E., Schnitzer, J.E., Oh, P., Lisanti, M.P., Lodish, H.F., 1997. Flotillin and epidermal surface antigen define a new family of caveolae associated integral membrane proteins. J. Biol. Chem. 272, 1379313802.

Burridge, K., Wennerberg, K., 2004. Rho and Rac take center stage. Cell 116, 167179.

Caroni, P., Schwab, M.E., 1993. Oligodendrocyte and myelin associated inhibitors of neurite growth in the adult nervous system. Adv. Neurol. 61, 175179.

da Silva, J.S., Dotti, C.G., 2002. Breaking the neuronal sphere: regulation of the actin cytoskeleton in neuritogenesis. Nat. Rev. Neurosci. 3, 694704.

Davy, A., Robbins, S.M., 2000. Ephrin A5 modulates cell adhesion and morphology in an integrin dependent man ner. EMBO J. 19, 53965405.

de Rooij, J., Bos, J.L., 1997. Minimal Ras binding domain of Rafl can be used as an activation specific probe for Ras. Oncogene 14, 623625.

Fawcett, J.W., 1992. Intrinsic neuronal determinants of regeneration. Trends Neurosci. 15, 58 .

Fuhrmann, J.C., Kins, S., Rostaing, P., El Far, O., Kirsch, J., Sheng, M., Triller, A., Betz, H., Kneussel, M., 2002. Gephyrin interacts with dynein light chains 1 and 2, components of motor protein complexes. J. Neurosci. 22, 53935402.

Galbiati, F., Volonte, D., Goltz, J.S., Steele, Z., Sen, J., Jurcsak, J., Stein, D., Stevens, L., Lisanti, M.P., 1998. Identification, sequence and developmental expression of invertebrate flotillins from drosophila melanogaster. Gene 210, 229237.

Hall, A., 1998. Rho GTPases and the actin cytoskeleton. Science 279, 509514. 
Hazarika, P., Dham, N., Patel, P., Cho, M., Weidner, D., Goldsmith, L., Duvic, M., 1999. Flotillin 2 is distinct from epidermal surface antigen (ESA) and is associated with filopodia formation. J. Cell. Biochem. 75, 147159.

Hazarika, P., McCarty, M.F., Prieto, V.G., George, S., Babu, D., Koul, D., Bar Eli, M., Duvic, M., 2004. Up regulation of flotillin 2 is associated with melanoma progression and modulates expression of the thrombin receptor protease activated receptor 1. Cancer Res. 64, 73617369.

Kim, B., Leventhal, P.S., Saltiel, A.R., Feldman, E.L., 1997. Insulin like growth factor I mediated neurite outgrowth in vitro requires mitogen activated protein kinase activation. J. Biol. Chem. 272, 2126821273.

Kimura, A., Baumann, C.A., Chiang, S.H., Saltiel, A.R., 2001. The sorbin homology domain: a motif for the targeting of proteins to lipid rafts. Proc. Natl. Acad. Sci. USA 98, 90989103.

Kioka, N., Ueda, K., Amachi, T., 2002. Vinexin, CAP/ponsin, ArgBP2: a novel adaptor protein family regulating cyto skeletal organization and signal transduction. Cell Struct. Funct. 27, 17

Kuhn, T.B., Brown, M.D., Bamburg, J.R., 1998. Rac1 dependent actin filament organization in growth cones is necessary for beta1 integrin mediated advance but not for growth on poly D lysine. J. Neurobiol. 37, 524540.

Kurokawa, K., Nakamura, T., Aoki, K., Matsuda, M., 2005. Mechanism and role of localized activation of Rho family GTPases in growth factor stimulated fibroblasts and neuronal cells. Biochem. Soc. Trans. 33, 631634.

Lang, D.M., Lommel, S., Jung, M., Ankerhold, R., Petrausch, B., Laessing, U., Wiechers, M.F., Plattner, H., Stuermer, C.A., 1998. Identification of reggie 1 and reggie 2 as plasmamembrane associated proteins which cocluster with activated GPI anchored cell adhesion molecules in non caveolar micropatches in neurons. J. Neurobiol. 37, 502523.

Langhorst, M.F., Reuter, A., Stuermer, C.A., 2005. Scaffold ing microdomains and beyond: the function of reggie/ flotillin proteins. Cell. Mol. Life Sci. 62, 22282240.

Langhorst, M.F., Genisyuerek, S., Stuermer, C.A., $2006 a$. Accumulation of FlAsH/Lumio green in active mitochon dria can be reversed by beta mercaptoethanol for specific staining of tetracysteine tagged proteins. Histochem. Cell Biol. 125, 743747.

Langhorst, M.F., Reuter, A., Luxenhofer, G., Boneberg, E.M., Legler, D.F., Plattner, H., Stuermer, C.A., 2006 b. Preformed reggie/flotillin caps: stable priming platforms for macrodomain assembly in T cells. FASEB J. 20, 711713.

Langhorst, M.F., Solis, G.P., Hannbeck, S., Plattner, H., Stuermer, C.A., 2007. Linking membrane microdomains to the cytoskeleton: regulation of the lateral mobility of reggie 1 /flotillin 2 by interaction with actin. FEBS Lett. 581, 46974703.

Malaga Trillo, E., Laessing, U., Lang, D.M., Meyer, A., Stuermer, C.A., 2002. Evolution of duplicated reggie genes in zebrafish and goldfish. J. Mol. Evol. 54, 235245.

Mitsushima, M., Suwa, A., Amachi, T., Ueda, K., Kioka, N., 2004. Extracellular signal regulated kinase activated by epidermal growth factor and cell adhesion interacts with and phosphorylates vinexin. J. Biol. Chem. 279, 3457034577.

Nakamura, T., Aoki, K., Matsuda, M., 2005. FRET imaging in nerve growth cones reveals a high level of RhoA activity within the peripheral domain. Brain Res. Mol. Brain Res. 139, 277287.

Neumann Giesen, C., Falkenbach, B., Beicht, P., Claasen, S., Luers, G., Stuermer, C.A., Herzog, V., Tikkanen, R., 2004. Membrane and raft association of reggie 1/flotillin 2: role of myristoylation, palmitoylation and oligomerization and induction of filopodia by overexpression. Biochem. J. 378, 509518.

Rajendran, L., Masilamani, M., Solomon, S., Tikkanen, R., Stuermer, C.A., Plattner, H., Illges, H., 2003. Asymmetric localization of flotillins/reggies in preassembled platforms confers inherent polarity to hematopoietic cells. Proc. Natl. Acad. Sci. USA 100, 82418246.

Recio Pinto, E., Rechler, M.M., Ishii, D.N., 1986. Effects of insulin, insulin like growth factor II, and nerve growth factor on neurite formation and survival in cultured sympathetic and sensory neurons. J. Neurosci. 6, 12111219.

Ren, X.R., Ming, G.L., Xie, Y., Hong, Y., Sun, D.M., Zhao, Z.Q., Feng, Z., Wang, Q., Shim, S., Chen, Z.F., Song, H.J., Mei, L., Xiong, W.C., 2004. Focal adhesion kinase in netrin 1 signaling. Nat. Neurosci. 7, 12041212.

Revenu, C., Athman, R., Robine, S., Louvard, D., 2004. The co workers of actin filaments: from cell structures to signals. Nat. Rev. Mol. Cell Biol. 5, 635646.

Ribon, V., Herrera, R., Kay, B.K., Saltiel, A.R., 1998. A role for CAP, a novel, multifunctional Src homology 3 domain containing protein in formation of actin stress fibers and focal adhesions. J. Biol. Chem. 273, 40734080.

Schulte, T., Paschke, K.A., Laessing, U., Lottspeich, F., Stuermer, C.A., 1997. Reggie 1 and reggie 2, two cell surface proteins expressed by retinal ganglion cells during axon regeneration. Development 124, 577587.

Slaughter, N., Laux, I., Tu, X., Whitelegge, J., Zhu, X., Effros, R., Bickel, P., Nel, A., 2003. The flotillins are integral membrane proteins in lipid rafts that contain TCR associated signaling components: implications for $\mathrm{T}$ cell activation. Clin. Immunol. 108, 138151.

Solis, G.P., Hoegg, M., Munderloh, C., Schrock, Y., Malaga Trillo, E., Rivera Milla, E., Stuermer, C.A., 2007. Reggie/ flotillin proteins are organized into stable tetramers in membrane microdomains. Biochem. J. 403, 313322.

Stuermer, C.A., Bastmeyer, M., Bahr, M., Strobel, G., Paschke, K., 1992. Trying to understand axonal regenera tion in the CNS of fish. J. Neurobiol. 23, 537550.

Stuermer, C.A., Lang, D.M., Kirsch, F., Wiechers, M., Deininger, S.O., Plattner, H., 2001. Glycosylphosphatidyl inositol anchored proteins and fyn kinase assemble in noncaveolar plasma membrane microdomains defined by reggie 1 and 2. Mol. Biol. Cell 12, 30313045.

Suwa, A., Mitsushima, M., Ito, T., Akamatsu, M., Ueda, K., Amachi, T., Kioka, N., 2002. Vinexin beta regulates the anchorage dependence of ERK2 activation stimulated by epidermal growth factor. J. Biol. Chem. 277, 1305313058. 